\title{
"Portray cultures other than ours": How children's literature is being used to support the diversity goals of the Australian Early Years Learning Framework
}

\author{
Helen Adam $^{1}$ (D) . Caroline Barratt-Pugh ${ }^{1}$ (D) Yvonne Haig $^{1}$
}

Received: 5 July 2018 / Accepted: 8 January 2019 / Published online: 20 January 2019

(c) The Author(s) 2019, corrected publication 2019

\begin{abstract}
Catering for diversity within birth to 5-year-old settings continues to be an on-going concern for policy makers and educators worldwide. This research contributes to discussion on the value of children's literature in achieving international principles of diversity and, in particular, the Principles, Practice and Outcomes outlined in the Australian Early Years Learning Framework. The article considers the selection and use of children's literature related to diversity, as well as what influences these processes. Seventeen educators from five long day care centres located in or near the Perth metropolitan area participated in the study. Data were drawn from interviews and a book audit. The findings revealed educators had limited understandings of the role of literature in acknowledging and valuing diversity and rarely used it to promote the diversity-related outcomes of the EYLF. The key challenges which emerged from the findings concerned beliefs of educators, professional learning and the application of the EYLF in practice.
\end{abstract}

Keywords Long day care $\cdot$ Literature $\cdot$ Diversity $\cdot$ Policy implementation · Inclusive curriculum

Helen Adam

h.adam@ecu.edu.au

Caroline Barratt-Pugh

c.barratt-pugh@ecu.edu.au

Yvonne Haig

yghaig@gmail.com

1 School of Education, Edith Cowan University, 2 Bradford Street, Mount Lawley, WA 6050, Australia 


\section{Introduction}

Over the past 25 years, recognising and including diversity within education settings and programs has become a focus of policy makers and educators worldwide, largely due to the rapid increase in global integration and international mobility since the 1990s. In Australia, particularly since becoming a signatory to the United Nations Convention on the Rights of the Child in 1989, educational policy has promoted recognition of and respect for diverse families, cultures, languages and values. This attention to diversity is reflected in the current national policies guiding early childhood education in Australia. These policies have been developed and applied since 2008 when this area of responsibility moved from individual states to the national Australian Government. Since then, the education of young children has been included in the government's National Quality Agenda [NQA] and subject to the National Quality Standard [NQS] (Australian Children's Education and Care Quality Authority 2012). The Early Years Learning Framework [EYLF] (Australian Government Department of Education, Employment and Workplace Relations \{DEEWR 2009) provides guidance in the application of this standard to the curriculum of all early education and care settings for children aged 0-5 years of age.

The EYLF requires educators to provide a curriculum that values and celebrates the diversity within and between families, cultures and communities. This attention to diversity is reflected in the three key elements of the EYLF: Principles, Practice and Outcomes. The Principles underpin practice and, in relation to diversity, suggest educators promote children's learning by 'valuing the social and cultural contexts of children and their families' (DEEWR 2009, p. 14). This is particularly apparent in Principle 4: Respect for diversity which describes the way in which educators 'honour the histories, cultures, languages, traditions, child rearing practices and lifestyle choices of families' (DEEWR 2009, p. 13). The EYLF encompasses five learning outcomes which are interrelated and each one supports the child's developing sense of belonging, being and becoming in an increasingly diverse world. In particular, Outcome 2: Children are connected with and contribute to their world, identifies 'Children respond to diversity with respect' as a key element (DEEWR 2009, p. 26). These linked components of the EYLF direct educators to respect and value all children and their families and backgrounds when implementing both the planned and unplanned curriculum. Such an approach assists educators to meet the challenge of preparing children to live in a society that is rapidly changing and where issues such as race, ethnicity, gender, ability and social background impact the benefits enjoyed by different groups (Bennett et al. 2018; Boutte et al. 2008; O'Neill 2010). The authors recognise, that as outlined by Bennet et al. (2018) and others (Boutte et al. 2008; O'Neill 2010), diversity encompasses many aspects, all of which deserve equal and equitable attention and inclusion in educational policy and practice. Similarly, the requirements of the EYLF place an expectation on educators to consider and address all aspects of diversity in their practice. However, for the purpose of the study being reported in this paper, the authors have focused on cultural and linguistic diversity. 
The EYLF includes texts as a means of exploring, valuing and encouraging appreciation and use of diverse language and cultural backgrounds; building on children's existing knowledge and language; providing print in home languages and exploring, listening to and appreciating diverse perspectives (DEEWR 2009). In doing so, the EYLF recognises that texts are culturally constructed artefacts that can promote consideration of diverse perspectives (DEEWR 2009). The EYLF encourages educators to share oral and written stories from Aboriginal and Torres Strait Islander traditions, those from our geographic neighbours and those brought by new citizens to Australia. As young children engage with literature, there is an emphasis both on 'sharing the enjoyment of language and texts' and on beginning 'to understand and evaluate ways in which texts construct identities and create stereotypes' (DEEWR 2009, p. 28). Thus texts have a critical role to play in supporting diversity in early childhood.

\section{The role of literature}

There are many forms of texts and the EYLF defines texts as "things that we read, view and listen to and that we create in order to share meaning" (2009, p. 46). For the purpose of this paper, we examine children's literature books, as one form of text that has the potential to support diversity.

The benefits of sharing books with young children are well known and well researched. Evidence consistently shows that frequent exposure to literature through book sharing and book reading opportunities has a significant impact on children's oral language development, early reading skills and future reading proficiency (Fleer and Raban 2005; Mol and Bus 2011; NELP 2008). In addition, social skills and understandings can be developed through book sharing. Examining character traits of key characters in children's books can teach children about important qualities such as friendship, cooperation, perseverance, respect and honesty (Kara-Soteriou and Rose 2008). Furthermore, children's books can be used to "explore feelings and affirm notions of acceptance, safety and wellbeing" (Zeece and Stolzer 2002, p. 47).

Importantly, and with strong parallels to the outcomes and principles of the EYLF, evidence suggests that children's literature is critical in fostering a developing sense of identity and belonging for all children (Kara-Soteriou and Rose 2008; Moss 2002; O'Neill 2010). Sharing books with children exposes them to new ways of thinking and being that can impact their developing sense of identity and sense of belonging, as well as exposing them to ideas, viewpoints and knowledge different to their own.

Using inclusive literature that represents diversity helps to engender a sense of pride in children and affirms their identity, their families and their communities (Bennett et al. 2018). Texts are a powerful means of helping children to understand themselves and others as they act as both a 'mirror' of personal identity and experiences and a 'window' onto the diversity of the world (Cox and Galda 1990), thus potentially supporting cross-cultural understanding (Harper and Brand 2010) and helping children to "make connections, form relationships and create community with others" (Short 2012, p. 9). In addition, literature has the capacity to broaden 
children's understanding of the world by providing vicarious experiences they otherwise would not have had (Lowery and Sabis-Burns 2007).

Literature also plays an important role in disrupting dominant discourses and examining issues of diversity (Boutte et al. 2011). For example, there are many studies that illustrate the way in which young children reproduce and rework societal discourse on race through their everyday experiences (Tenorio 2008; Van Ausdale and Feagin 2001). It is argued that early childhood settings are not neutral spaces, but places where children learn how diversity is constructed and valued. Lowery and Sabis-Burns (2007) argue that many children spend their early years in a monocultural environment forming their attitude to others through a range of stereotypes captured in the world of paper-based and digital media they inhabit. This in turn can result in a sense of exclusion or "othering" for those children from non-dominant cultures. Literature can be used to broaden the understanding of the pluralistic nature of society and challenge the prevailing values inherent in much of the dominant discourse. Short (2012) argues that literature provides a way "to move between local and global cultures and to explore the ways in which people live and think in cultures that differ from our own" (p. 9).

Hence the selection and use of books that encapsulate diversity becomes a crucial part of early childhood education. Research indicates that children need access to authentic and accurate representations and role models related to their cultural, linguistic and social backgrounds (Jones Diaz and Harvey 2002; Morgan 2009). Without this recognition of diversity, their participation in the curriculum can be both intellectually and emotionally challenging. Emotions such as fear, anxiety and doubt impact a child's well-being when their world is invisible or presented in a stereotypical or discriminatory manner, or as an 'other' perspective (Dunlap 2012).

\section{Selection and use of literature}

Although there may be increasing recognition of the importance of texts in including and broadening children's experiences, the selection of texts that represent diversity is problematic. Research over the last two decades has unequivocally found that the world presented in children's books is "predominately upper middle class, heterosexual, non-disabled, English speaking, and male" (Crisp et al. 2016, p. 29). Although there has been some increase in the publication of books that are more inclusive, many are based on stereotypes, misrepresentation, biases and discrimination. Issues such as authors from dominant cultures writing about non-dominant cultures with little knowledge or understanding, the failure to include characters with whom children from diverse backgrounds can identify and Indigenous groups being represented in stereotypical and superficial ways make the task for educators even more difficult (Boutte et al. 2008; Morgan 2009). Mendoza and Reese (2001) argue that for many children, images of themselves, their experiences and the world in which they live may not be visible in their encounters with texts.

Furthermore, the quality and availability of diverse literature as well as the selection of texts can be influenced by a range of factors, including the role of adults in the selection and use of children's literature and educators' beliefs and professional 
knowledge, or lack of knowledge, about the importance, selection and use of such potentially powerful literature in children's lives. Of particular importance are the potential biases educators may hold that may influence their selection of children's literature (Johnston et al. 2007) which could have implications for considered use of children's literature to support principles of diversity.

The influence of adults, together with their beliefs and professional knowledge, in this process is evident in a Canadian study which found that pre-service teachers favoured children's texts which presented societal perspectives and themes that were familiar to them and reflected their own spatio-temporal backgrounds (Johnston et al. 2007). Researchers in the US and Australia have also found that the lack of diverse perspectives in the literature texts available was due to the educators involved in their selection and use not seeing 'white' as a race (Buchori and Dobinson 2015; Spina and Tai 1998;) or as a "focus for critique and analysis" (Spina and Tai 1998, p. 37). This, in turn, influences educators' curricular choices contributing to practice that reinforces the dominant culture as preferable and superior.

Mendoza and Reese (2001) suggest that some early childhood educators find sourcing and evaluating the quality of diverse literature an enormously challenging task, resulting in little or no literature that represents the pluralistic nature of society. This is confirmed by studies which have found that some early childhood educators have little knowledge about multicultural literature and there is limited evidence of literature that represents diversity in early childhood programs (Adam et al. 2017; Brinson 2012; Crisp et al. 2016).

In addition, because as a social construct diversity is complex, ever changing and multi-dimensional (Boyd et al. 2015), identifying and categorising multicultural books and book collections is also problematic. Previous studies that have defined and categorised multicultural literature have used such definitions as ethnicity (Boutte et al. 2008), differing cultural groups (Brinson 2012) and colour (Bishop 1997). Bishop claims that colour is one of the most divisive issues in society and the 'absence of such literature has constituted one of the most glaring omissions in the canon of children's literature' (Bishop 1997, p. 35). In addition, "colour is relatively easy to identify, whereas 'culture' and 'ethnicity' is complex and multifaceted" (Adam et al. 2017, p. 90). The need to access appropriate guidelines to select and evaluate quality multicultural literature for students to read has been identified as an important means of redressing the balance (Harper and Brand 2010; Lowery and Sabis-Burns 2007).

Selecting appropriate literature is only the beginning of creating an inclusive curriculum; using diverse literature with young children is also complex and multifaceted. How children engage with literature impacts their developing understanding of themselves and their world (Short 2012). Research suggests that educators are often reluctant to discuss issues about equality, power, attitudes and values because of their unfamiliarity with the knowledge base, a lack of confidence and availability of resources (Boutte et al. 2011) as well as the mistaken belief that one book about a group can adequately portray that group's experiences (Mendoza and Reese 2001). In addition, the construction of children from diverse cultural and linguistic backgrounds as 'other' who need to learn English and be assimilated into the dominant culture, leads to superficial teaching and learning about diversity (Buchori and 
Dobinson 2015; Colombo 2005). Ultimately, this suggests that interactions between pedagogical practices, children's literature and children's learning will depend upon educators' professional knowledge, their training, skills and judgements and the quality and relevance of the literature they share with children.

In summary, literature is an enabler of 'culturally responsive pedagogy' (SoutoManning 2009, p. 50). In this type of pedagogy, selecting texts, reading with children, working with children to gain meaning from the literature and challenging children to express their ideas through a range of media is important (Harper and Brand 2010). Children need active involvement in learning that involves engaging with quality literature and exploring their ideas through books that reflect their own cultures and reflect not only diversity within their early childhood setting but also the wider world (Klefstad and Martinez 2013). This places important demands on educators worldwide in meeting policy and program expectations related to diversity. In Australia, the nature of educators' work requires them to apply knowledge of the EYLF, engage in the teaching and learning process and partner with families and the broader community in ways which support children's learning to meet the challenges of a diverse and ever changing 21st century. The inclusion and exploration of a range of diverse literature is central to achieving these goals. Given the importance of the educator as mediator in the use of children's literature, it is important to investigate the attitudes and practices of the educators themselves.

\section{The present study}

Given the key role educators play in the use of literature to achieve goals related to diversity, this study investigated their perceptions and reported practices through the following research questions:

What are educators' perceptions of the role of children's literature in supporting the EYLF Principles, Practice and Outcomes related to diversity?

What do educators report about how they select and use children's literature related to diversity?

\section{Methodology}

This paper reports on part of a broader study undertaken within the epistemological framework of sociocultural theory and using a qualitative methodology. This form of inquiry centres on the way participants interpret and make sense of their experiences to capture their version of reality (Denzin and Lincoln 2005). It involves the collection of a variety of empirical materials within the context being investigated, in order to uncover the meaning of social phenomena as experienced by participants (Marshall and Rossman 2011). Interpretative analysis through inductive and deductive logic enables patterns, categories and themes evident within the data sets to be identified (Marshall and Rossman 2011). 


\section{Participants}

A purposeful sample of five long day care centres in the Perth metropolitan area, Western Australia were selected. Demographic data from the 2006 Australian Census (Australian Bureau of Statistics 2006) were used to select centres that represented cultural and socio-economic diversity. All centres are located in areas of significant ethnic diversity, with at least one-quarter of their populations born overseas. The selection was further refined by the identification of different operators. The final selection included LDCCs operated by a charitable institution, a religious organisation, a private school, a local government and a commercial enterprise.

Altogether 17 educators agreed to take part in the research, with qualifications ranging from an Education Assistant Diploma to a Bachelor of Education. These included the centre coordinator and an educator from each of the baby, toddler and kindergarten rooms in the five centres. Centre 2 had three kindergarten rooms so the participant selected was the lead educator from the room catering for the 4-year-old group to ensure consistency with the remaining centres. Centre 3, was school-based with one room catering for toddlers and kindergarten children. In the fifth centre, the centre coordinator was the educator in the baby room. The inclusion of educators from each of the areas of the centres provided a more comprehensive view of practice with children's literature in early childhood settings.

\section{Data collection}

Two methods of data collection were employed to allow for triangulation and increase the reliability of the findings (Creswell 2005). These were semi-structured interviews, and an audit of the children's literature in each LDCC.

Semi-structured interviews took place in the participants' LDCC using openended questions. Interviews varied from between 10 and 30 min. Participants were asked to describe the place of children's literature in responding to the EYLF with a particular focus in relation to diversity. They were encouraged to elaborate on their responses and invited to describe how they selected and used children's literature to support diversity. They were also invited to add any other comments at the end of the interview.

An audit of children's literature texts was undertaken in each of the centre rooms, including noting their availability to staff and children. Qualitative content analysis was used to systematically identify, record and analyse each book. Hsieh and Shannon (2005, p. 1278) define qualitative content analysis as "a research method for the subjective interpretation of content of text data through the systematic classification process of coding and identifying themes or patterns".

\section{Analysis}

The semi-structured interview data were analysed using an inductive approach in which "frequent, dominant or significant themes inherent in raw data emerge from 
the application of a systematic analytical process" (Thomas 2006, p. 238). Using Braun and Clarke's (2006) five stages of thematic analysis, the transcripts were read and re-read, initial codes generated and emergent themes established. The themes were reviewed and checked for fidelity then finally each theme was carefully defined and named. In line with the framework of sociocultural theory, in which participants interpret and make sense of their experiences to capture their version of reality (Denzin and Lincoln 2005), extensive participant quotation was utilised with a goal of building "an in-depth picture of participants' understandings and responses" (Buchori and Dobinson 2015, p. 73) and thus to authenticate the analysis.

An audit of the children's books was undertaken in the kindergarten, toddler and baby rooms of four centres and the combined toddler/kindergarten room of LDCC three. The audit included books that were available to children and those that were stored separately, accessible only to educators. The storage systems and accessibility of the books were also documented and all information then entered into a Microsoft Excel spread sheet.

An initial analysis of the books according to genre, themes, characters, images and general condition was undertaken to enable triangulation with interviews and observations regarding the selection and use of literature in the centres. The books were then categorised for racial diversity. For the purpose of this study, categorisation was guided by the work of Bishop using skin colour to categorise human representation in children's literature (Bishop 1997). This enabled an analysis of whether and to what extent people of colour were represented in the book collections. Books were categorised by proportion of colour representation.

The findings from the book audit are reported in a previous article by the authors (Adam et al. 2017), while this article reports on the comparison of the book data with the interview data to check and confirm the emergent themes.

\section{Ethics}

The research was conducted with ethical approval granted through Edith Cowan University processes, project number 6389. Participants were given an information letter outlining the purpose of the research and their involvement. They were informed about confidentiality and security and their right to withdraw. All participants agreed to take part and signed a consent form.

\section{Findings and discussion}

Six key and interrelated themes emerged from the data. These themes are a construction of diversity as visual and linguistic difference or 'other'; the value and place of books; responding to diversity/children's interests; mono-cultural book collections; diversity as peripheral to centre programs and the need for more training and support. This section reports and discusses these findings, their interrelationships and the role of children's literature in achieving the Principles, Practice and Outcomes related to diversity in the EYLF. 


\section{Construction of diversity as visual and linguistic difference or 'other'}

Educators' perceptions about the role of books in addressing diversity suggested a construction of diversity as cultural and linguistic. Only one educator referred to disability and religion. Furthermore, educators considered cultural and linguistic diversity to only relate to children, who were "visually different" and/or had limited English language proficiency. This focus on visual difference is consistent with the evidence that cultural diversity is often defined as relating to "people of colour" (Bishop 1997, p. 35) This shows a restricted understanding of diversity inconsistent with that of the EYLF (DEEWR 2009) and much narrower than more widely accepted definitions which include aspects such as family structures, ethnicity, lifestyle choices, race, gender, ability and social background (Bennett et al. 2018; Boutte et al. 2008; O'Neill 2010).

The twelve educators who mentioned the importance of considering diverse backgrounds, referred specifically to the cultural backgrounds of children in their centre and the importance of introducing children to 'other' cultures when using books. For example, one educator stated that they needed more books from the "cultures where mum and dad came from". Another, that books would "expose them [children] to different cultures, will engage them and make them start thinking about asking questions and then obviously that leads to something else". This notion of 'other' was also evident when the educators talked about diverse books as those "from around the world" or that "portray other cultures other than ours...other places that people live". This perception promotes a construction of diversity as being outside children's lived experiences and, as found by Buchori and Dobinson (2015, p. 15), "despite recognising the need to acknowledge ...cultural differences... participants adopted a 'one size fits all' approach".

Seven of the educators talked about addressing diversity by referring to books in the "different languages" of particular children, usually recently arrived and not fluent in English. One Educator reported bringing in "books from Japan that have got Japanese language" to support a Japanese child and another making a book about Vietnam to support a Vietnamese child. While this reflects an intention to be inclusive, one educator who took this approach stressed the caveat that "most of our parents prefer us to teach them English anyway" suggesting that they believe that teaching children to speak English addresses the wishes of parents and is of greater importance than supporting children's first language. This echoes evidence from Amigo (2012) and Buchori and Dobinson (2015) that educators believe that culturally diverse children should speak English. This attitude can be part of a deeper issue of educators perceiving, and thus perpetuating a view, of the dominant culture as being superior or preferable to non-dominant cultures. Consequently, efforts made with the intention of promoting inclusivity can, instead, contribute to a sense of 'othering' experienced by children from non-dominant groups.

\section{The value and place of books}

Educators spoke confidently about intentionally selecting and using books to assist the development of children's language and literacy $(n=12)$, and to convey 
messages about appropriate social behaviour and self-regulation $(n=10)$. This shows that the educators placed value on the sharing of books for children's oral language development, early reading skills and future reading proficiency (Fleer and Raban 2005; Mol and Bus 2011; NELP 2008). These educators also recognised and valued the use of books to help develop social skills such as sharing, being polite and cooperating with others (Kara-Soteriou and Rose 2008; Zeece and Stolzer 2002).

However, educators seemed uncertain or unaware of the potential and importance of books in enabling culturally responsive pedagogy (Souto-Manning 2009) Only one educator mentioned considering intentionally selecting books that represented the cultural backgrounds of children in the centre, explaining, "having books that are relevant to children, so that they know there are different cultures is important". Although twelve educators mentioned the importance of considering children's diverse backgrounds when using books, eleven did so briefly and in a tentative way (Colby and Lyon 2004; Brinson 2012) that contrasted sharply with the confident way they talked about the use of books to develop literacy, numeracy and, particularly, social skills and preferred behaviours. This tentativeness was evident in how they described the few resources related to diversity that they had in their centres, typically using vague terms such as ' $f e w$ ', and, 'sorts of things'. For instance, one educator said, "from those sorts of things, multicultural [pause] any of those Aboriginal things" and another, "there are a few families that have got cultural, like, religions and stuff...I think we have got some books like that, and also disabilities, that sort of thing you could add [to provide for children's diverse backgrounds]". Given that the educators were positive and confident regarding the value of using books to educate children about social and emotional skills, attributes and behaviours, it is significant that they did not see the value of books for educating children about diversity. Perhaps of greater concern is that they appeared to be unaware that for all children to have equitable opportunity to achieve the desired positive social and emotional outcomes, as well as early literacy development, there was a need to use literature inclusive of all children's backgrounds. Therefore, while the educators were confident regarding children "sharing the enjoyment of language and texts" (DEEWR 2009, p. 28), they lacked awareness of the need, and seemed to be overlooking the opportunity, for young children "to understand and evaluate ways in which texts construct identities and create stereotypes" (DEEWR 2009, p. 28).

Moreover, educators' references to diversity were vague. For example, an educator in one kindergarten room said, "we do have a bit of diversity. I mean we've got a few books about we're all different and things like that". One centre coordinator said, "and also about different cultures as well. You know, why people are different and all that stuff". Five educators did not mention diversity specifically with two of these indicating that they "hadn't really thought about it". These findings echo other studies which identified educators' lack of knowledge, confidence and consideration in relation to diversity and children's literature (Colby and Lyon 2004; Brinson 2012). This suggests a lack of cultural competency among the educators, the impact of which can result in a curriculum in which the worlds of children from non-dominant cultures are invisible, leading to fear, anxiety or doubt, impacting a child's well-being (Dunlap 2012). 


\section{Mono-cultural book collections}

Given the educators' construction of diversity and culture as being about visual difference, the books were analysed for portrayal of visual difference (i.e. non-Caucasian races) in the human characters. Less than 5\% of the books portrayed any people of appearance other than Caucasian and in most of these the main characters were Caucasian, with only $1 \%$ of the books having a main character of non-Caucasian appearance. So despite the educators' tentative recognition of the value of books reflecting diversity, the books available in each centre were strikingly mono-cultural (Adam et al. 2017). This is consistent with other research which found only a very small percentage of books in early childhood book collections included representation of diversity (Boutte et al. 2008; Crisp et al. 2016).

The lack of diversity in the book collections was reflected in the educators' reported preferences and use of books discussed earlier in this article. Furthermore, while the educators reported providing a range of activities before, during and after reading books, there was no reference to considering children's backgrounds when planning or conducting these. This is despite the importance of considering children's backgrounds (Dunlap 2012; Guo 2015; Hyun 2007; Jones Diaz and Harvey 2002; Klefstad and Martinez 2013; Morgan 2009) and using these opportunities to learn about unfamiliar cultures and so promote the valuing of cultural diversity and to build positive identities (Boutte et al. 2008; Moss 2002).

Again, given the value educators placed on using books to develop both literacy and social and emotional outcomes, these same outcomes could be compromised for children from minority backgrounds through the potentially damaging effects of using only mono-cultural literature.

\section{Diversity as peripheral}

Even when children's diverse backgrounds were acknowledged through the provision of books, the educators reported this as peripheral and additional to, rather than part of, their main programs. This was also evidenced in the way books reflecting diversity tended to be borrowed from other agencies rather than owned by the centres. Three centres reported sometimes borrowing a box of books which had "multicultural type things in it" from an external early childhood organisation. Others reported borrowing books from the local library or using those brought in by parents, indicating that these books were considered extra or special and not part of the centre book collections. This 'gap' in the provision of diverse texts supports evidence that some educators find sourcing and evaluating the quality of diverse literature an enormously challenging task, resulting in little or no literature that represents the pluralistic nature of society (Mendoza and Reese 2001). The outcome of this gap once again positions representations of non-dominant cultures and languages as 'other' (Buchori and Dobinson 2015) and adds to evidence that for many educators, multicultural literature was not an important part of their program (Colby and Lyon 2004). 
Although some educators mentioned using a text in "their parents' language" with Chinese, Vietnamese, Afrikaans or Mumbai background children, most references were to having "multicultural" or "language' books" "just basically there for the children so they see them so it just becomes part of their day" or that they "don't make a big deal about it but they're just there...". This suggests that these educators did not attach importance or were reluctant to engage children in discussion around diversity, preferring the books to become 'normalised', risking a lack of recognition of diversity and avoiding issues of representation, power and inclusivity (Boutte et al. 2011). One educator explained that although she recognised the importance of using books that represented the children's cultural backgrounds she could "only give across what I know" and that the children's parents and the educators who were Aboriginal would be more able to promote diversity. This avoidance of the complex and multifaceted aspects of power, inclusivity and representation contributes to a 'silence' in which children are deprived of the opportunity to actively engage with literature "to move between local and global cultures and to explore the ways in which people live and think in cultures that differ from our own" (Short 2012, p. 9).

\section{The need for training and support}

The lack of attention to the representation of diversity in book collections in the context of discussing the EYLF, despite the considerable attention this framework gives to inclusivity issues, is perhaps not surprising when the educators' comments about the EYLF are taken into account.

The importance of training as a means of helping educators to promote diversity and engage in challenging issues related to inclusivity has been well established (Johnston et al. 2007; Premier and Miller 2010; Mendoza and Reese 2001). However, most educators had only attended one or two professional development sessions about the EYLF, which were reported as mainly procedural or repeating information available in printed materials. Only seven of the educators had attended more extensive professional development and three of these were centre coordinators, who, in turn, were mainly responsible for training the staff in their centres. On the whole they felt a lack knowledge and preparedness to implement the EYLF. It appeared that what little training had been provided or attended did not give attention to the important aspects of cultural competency that underpin the principles of the EYLF.

\section{Conclusion and recommendations}

This study found that the selection and use of children's literature in five long day care centres in Western Australia did not reflect the Principles, Practice and Outcomes related to diversity in the EYLF. Educators demonstrated a limited understanding of diversity with most educators viewing diversity as being about visual differences and language background and peripheral to their centre's programs. Where educators related diversity to culture they tended to construct this as 'other' or 'different' and outside the lived experiences of the majority of children in their care. Reported book 
sharing and book-related activities with children did not reflect consideration or focus on diversity. Books were predominantly used by educators to develop language and literacy understandings or social and emotional outcomes. Given these findings it is not surprising that the collections of books available in the centres, the educators' book shelves and the children's book corners had few examples of texts that could be considered inclusive of children from diverse backgrounds.

Overall, these findings suggest that educators would experience difficulty in appropriately applying culturally responsive pedagogy through the use of inclusive texts (Souto-Manning 2009) a challenge also found by others (Brinson 2012; White 2009). This adds to a body of work demonstrating the global nature of this problem.

Given these findings, it would seem that some form of on-going professional learning and practice is necessary to redress the balance and to assist educators to both understand and implement the selection and use of inclusive literature, thus leading to improved cultural competency. Such training would assist to create an inclusive curriculum that supports the learning and development of all children. Failure to address this issue will continue to impact children through a potential lifelong negative influence of using exclusive literature (Boutte et al. 2008; Brinson 2012) and run the risk of many children remaining at a disadvantage in educational contexts in which they are invisible and their voices are not heard or valued.

Certain limitations apply to the study including the size of the sample (17 educators from five centres), which has caused us to be necessarily tentative in generalising our findings beyond this group. Nevertheless, the findings do point to implications beyond this particular group of educators. Further, the study was undertaken in the very early stages of the implementation of the EYLF. These limitations suggest further research is needed to investigate educators' understandings related to diversity, and whether more recent implementation strategies have led to changes in the selection, use and value of books. Such studies should also include the voices of children, families and communities.

Acknowledgements The authors thank Professor Bronwen Cowie for her valuable advice and support in the development of this article.

Open Access This article is distributed under the terms of the Creative Commons Attribution 4.0 International License (http://creativecommons.org/licenses/by/4.0/), which permits unrestricted use, distribution, and reproduction in any medium, provided you give appropriate credit to the original author(s) and the source, provide a link to the Creative Commons license, and indicate if changes were made.

\section{References}

Adam, H., Barratt-Pugh, C., \& Haig, Y. (2017). Book collections in long day care: Do they reflect racial diversity? Australasian Journal of Early Childhood, 42(2), 88-96. https://doi.org/10.23965/ AJEC.42.2.11.

Amigo, M. F. (2012). Liminal but Competent: Latin American Migrant children and school in Australia. Child Studies in Diverse Contexts, 2(1), 61-75.

Australian Bureau of Statistics (ABS). (2006). Perth: A social atlas 2006 (Cat. No. 200.5). Retrieved from https://www.abs.gov.au/AUSSTATS/abs@.nsf/DetailsPage/2030.52006. 
Australian Children's Education and Care Quality Authority. (2012). National Quality Standard. Retrieved November 14, 2015, from http://acecqa.gov.au/national-quality-framework/the-national-quality-standard.

Australian Government Department of Education Employment and Workplace Relations. (2009). Belonging, being \& becoming: The Early Years Learning Framework for Australia. Canberra: DEEWR.

Bennett, S., Gunn, A., Gayle-Evans, G., Barrera, E., \& Leung, C. (2018). Culturally responsive literacy practices in an early childhood community. Early Childhood Education Journal, 46(2), 241-248.

Bishop, R. S. (1997). Selecting literature for a multicultural curriculum. In V. J. Harris (Ed.), Using multi-ethnic literature in the K-8 classroom (pp. 1-20). Norwood: Christopher-Gordon.

Boutte, G. S., Hopkins, R., \& Waklatsi, T. (2008). Perspectives, voices, and worldviews in frequently read children's books. Early Education and Development, 19(6), 941-962. https://doi.org/10.1080/10409 280802206643.

Boutte, G. S., Lopez-Robertson, J., \& Costello, E. (2011). Moving beyond colorblindness in early childhood classrooms. Early Childhood Education Journal: Advance online publication. https://doi. org/10.1007/s10643-011-0457-x.

Boyd, F. B., Causey, L. L., \& Galda, L. (2015). Enriching variety in an era of common core state standards. The Reading Teacher, 68(5), 378-387.

Braun, V., \& Clarke, V. (2006). Using thematic analysis in psychology. Qualitative Research in Psychology, 3(2), 77-101.

Brinson, S. A. (2012). Knowledge of multicultural literature among early childhood educators. Multicultural Education, 19(2), 30.

Buchori, S., \& Dobinson, T. (2015). Diversity in teaching and learning: Practitioners' perspectives in a multicultural early childhood setting in Australia. Australasian Journal of Early Childhood, 40(1), 71-79.

Colby, S. A., \& Lyon, A. F. (2004). Heightening awareness about the importance of using multicultural literature. Multicultural Education, 11(3), 24.

Colombo, M. W. (2005). Empathy and cultural competence: Reflections from teachers of culturally diverse children. Beyond the Journal, 1-8. https://www.researchgate.net/profile/Michaela_Colom bo2/publication/255647288_Reflections_from_Teachers_of_Culturally_Diverse_Children/links 1564daa7708aeafc2aaaffcf9/Reflections-from-Teachers-of-Culturally-Diverse-Children.pdf?origi $\mathrm{n}=$ publication_detail.

Cox, S., \& Galda, L. (1990). Multicultural literature: Mirrors and windows on a global community (Children's books). The Reading Teacher, 43(8), 582.

Creswell, J. (2005). Educational Research: Planning, conducting \& evaluating qualitative and quantitative research (2nd ed.). Thousand Oaks, CA: Sage Publications.

Crisp, T., Knezek, S., Quinn, M., Bingham, G., Girardeau, K., \& Starks, F. (2016). What's on our bookshelves? The diversity of children's literature in early childhood classroom libraries. Journal of Children's Literature, 42(2), 29-42.

Denzin, N., \& Lincoln, Y. (2005). Introduction: The discipline and practice of qualitative research. In Norman Denzin \& Yvonna Lincoln (Eds.), The SAGE handbook of qualitative research (pp. 1-32). Thousand Oaks, CA: Sage.

Dunlap, M. (2012). Thriving in a multicultural classroom. In C. P. Harvey \& M. J. Allard (Eds.), Understanding and managing diversity (5th ed., pp. 12-21). Upper Saddle River, NJ: Pearson/Prentice Hall.

Fleer, M., \& Raban, B. (2005). Literacy and numeracy: A review of the literature. Department of Education, Employment and Workplace Relations. Retrieved from http://foi.deewr.gov.au/system/files/doc/ other/literacy_and_numeracy_a_review_of_the_literature.pdf.

Guo, K. (2015). Teacher knowledge, child interest and parent expectation: Factors influencing multicultural programs in an early childhood setting. Australasian Journal of Early Childhood, 40(1), 63-70.

Harper, L. J., \& Brand, S. T. (2010). More alike than different: Promoting respect through multicultural books and literacy strategies. Childhood Education, 86(4), 224-233.

Hsieh, H. F., \& Shannon, S. E. (2005). Three approaches to qualitative content analysis. Qualitative Health Research, 15(9), 1277-1288.

Hyun, E. (2007). Cultural complexity in early childhood: Images of contemporary young children from a critical perspective. Childhood Education, 83(5), 261-266.

Johnston, I., Bainbridge, J., \& Shariff, F. (2007). Exploring issues of national identity, ideology and diversity in contemporary Canadian picture books. Papers: Explorations into Children's Literature, 17, 75.

Jones Diaz, C. J., \& Harvey, N. (2002). Other words, other worlds: Bilingual identities and literacy. In L. Makin \& C. J. Diaz (Eds.), Literacies in early childhood: Changing views challenging practice (pp. 175-195). Eastgardens, NSW: MacLennon \& Petty. 
Kara-Soteriou, J., \& Rose, H. (2008). A bat, a snake, a cockroach, and a fuzzhead: Using children's literature to teach about positive character traits. Young Children, 63(4), 30-36.

Klefstad, J. M., \& Martinez, K. C. (2013). Promoting young children's cultural awareness and appreciation through multicultural books. Young Children, 68(5), 74-78.

Lowery, R., \& Sabis-Burns, D. (2007). From borders to bridges: Making cross-cultural connections through multicultural literature (Promising practices). Multicultural Education, 14(4), 50.

Marshall, C., \& Rossman, G. (2011). Designing qualitative research (5th ed.). Los Angeles: Sage.

Mendoza, J., \& Reese, D. (2001). Examining multicultural picture books for the early childhood classroom: Possibilities and pitfalls. Early Childhood Research \& Practice, 3(2), n2.

Mol, S. E., \& Bus, A. G. (2011). To read or not to read: A meta-analysis of print exposure from infancy to early adulthood. Psychological Bulletin, 137(2), 267.

Morgan, H. (2009). Gender, racial, and ethnic misrepresentation in children's books: A comparative look. Childhood Education, 85(3), 187-190.

Moss, J. (2002). Understanding curriculum to support education for all. In M. Keefe \& S. Carrington (Eds.), Schools and diversity (2nd ed., pp. 128-144). Frenchs Forest NSW: Pearson Education Australia.

National Early Literacy Panel. (2008). Developing early literacy: Report of the National Early Literacy Panel. Washington, DC: National Institute for Literacy.

O'Neill, K. (2010). Once upon today: Teaching for social justice with postmodern picture books. Children's Literature in Education, 41, 40-51.

Premier, J. A., \& Miller, J. (2010). Preparing pre-service teachers for multicultural classrooms. Australian Journal of Teacher Education, 35(2), 35-48.

Short, K. (2012). Story as world making. Language Arts, 90(1), 9-17.

Souto-Manning, M. (2009). Negotiating culturally responsive pedagogy through multicultural children's literature: Towards critical democratic literacy practices in a first grade classroom. Journal of Early childhood Literacy, 9(50), 50-74.

Spina, S. U., \& Tai, R. H. (1998). The politics of racial identity: A pedagogy of invisibility. Educational Researcher, 27(1), 36-48.

Tenorio, R. (2008). Raising issues of race with young children. In A. Pelo (Ed.), Rethinking early childhood education (pp. 17-21). Milwaukee, WS: Rethinking Schools.

Thomas, D. (2006). A general inductive approach for analyzing qualitative evaluation data. American Journal of Evaluation, 27(2), 237-246.

Van Ausdale, D., \& Feagin, J. R. (2001). The first R: How children learn race and racism. Lanham, MD: Rowman and Littlefield.

White, J. (2009). Assessment in New Zealand early childhood education: A Bakhtinian analysis of toddler metaphoricity (Doctoral dissertation). Retrieved October 12, 2015 from http://arrow.monash.edu/ vital/access/manager/Repository/monash:34937

Zeece, P. D., \& Stolzer, J. (2002). Creating literature safety zones for children. Early Childhood Education Journal, 30(1), 47-52.

Helen Adam is an academic lecturer, researcher and Ph.D candidate at Edith Cowan University. Helen's research addresses the role and importance of quality inclusive literature in the social and emotional wellbeing of the child, with a particular focus on the importance of authentic representations and inclusion of cultural diversity in children's literature.

Caroline Barratt-Pugh is a Professor for the School of Education and the Director of the Centre for Research in Early Childhood at Edith Cowan University. She has lead numerous research projects and published extensively in her research interest areas which include early language and literacy learning and development, bilingual and multilingual families, early childhood pedagogy and practice and early intervention programs.

Yvonne Haig is an honorary lecturer at Edith Cowan University, having recently retired after more than eighteen years working in the area of EAL and applied linguistics. Yvonne also had extensive experience in the school system, both as a teacher and leader. The main focus of her work has been the education of children from diverse cultural, social and linguistic backgrounds. 